\title{
Concrete Compressive Strength by Means of Ultrasonic Pulse Velocity and Moduli of Elasticity
}

\author{
Bogdan Bolborea ${ }^{1,2, *}$, Cornelia Baera ${ }^{2,3,4}$, Sorin Dan ${ }^{1} \mathbb{D}$, Aurelian Gruin ${ }^{2}$, Dumitru-Doru Burduhos-Nergis ${ }^{5, *} \mathbb{D}$ \\ and Vasilica Vasile 6
}

check for updates

Citation: Bolborea, B.; Baera, C.; Dan, S.; Gruin, A.; Burduhos-Nergis, D.-D.; Vasile, V. Concrete Compressive Strength by Means of Ultrasonic Pulse Velocity and Moduli of Elasticity. Materials 2021, 14, 7018. https://doi.org/10.3390/ma14227018

Academic Editor: Jie Hu

Received: 3 November 2021

Accepted: 17 November 2021

Published: 19 November 2021

Publisher's Note: MDPI stays neutral with regard to jurisdictional claims in published maps and institutional affiliations.

Copyright: (c) 2021 by the authors. Licensee MDPI, Basel, Switzerland. This article is an open access article distributed under the terms and conditions of the Creative Commons Attribution (CC BY) license (https:/ / creativecommons.org/licenses/by/ $4.0 /)$.
1 Civil Engineering Faculty, Politehnica University of Timisoara, 300223 Timisoara, Romania; sorin.dan@upt.ro

2 NIRD URBAN-INCERC Timişoara Branch, 300223 Timisoara, Romania; cornelia.baera@incd.ro (C.B.); aurelian.gruin@incd.ro (A.G.)

3 Research Center in Engineering and Management, Politehnica University of Timisoara, 300191 Timisoara, Romania

4 Civil Engineering Faculty, IOSUD-UTCN Doctoral School, Technical University of Cluj-Napoca, 400020 Cluj-Napoca, Romania

5 Faculty of Materials Science and Engineering, Gheorghe Asachi Technical University, 700050 Iasi, Romania

6 NIRD URBAN-INCERC Bucharest Branch, 021652 Bucharest, Romania; valivasile67@yahoo.com

* Correspondence: bogdan.bolborea@student.upt.ro (B.B.); doru.burduhos@tuiasi.ro (D.-D.B.-N.); Tel.: +40-766-678-029 (B.B.)

\begin{abstract}
Developing non-destructive methods (NDT) that can deliver faster and more accurate results is an objective pursued by many researchers. The purpose of this paper is to present a new approach in predicting the concrete compressive strength through means of ultrasonic testing for non-destructive determination of the dynamic and static modulus of elasticity. For this study, the dynamic Poisson's coefficient was assigned values provided by technical literature. Using ultra-sonic pulse velocity (UPV) the apparent density and the dynamic modulus of elasticity were determined. The viability of the theoretical approach proposed by Salman, used for the air-dry density determination (predicted density), was experimentally confirmed (measured density). The calculated accuracy of the Salman method ranged between 98 and $99 \%$ for all the four groups of specimens used in the study. Furthermore, the static modulus of elasticity was deducted through a linear relationship between the two moduli of elasticity. Finally, the concrete compressive strength was mathematically determined by using the previously mentioned parameters. The accuracy of the proposed method for concrete compressive strength assessment ranged between 92 and $94 \%$. The precision was established with respect to the destructive testing of concrete cores. For this research, the experimental part was performed on concrete cores extracted from different elements of different structures and divided into four distinct groups. The high rate of accuracy in predicting the concrete compressive strength, provided by this study, exceeds $90 \%$ with respect to the reference, and makes this method suitable for further investigations related to both the optimization of the procedure and = the domain of applicability (in terms of structural aspects and concrete mix design, environmental conditions, etc.).
\end{abstract}

Keywords: concrete; compressive strength; NDT; ultrasonic pulse velocity; modulus of elasticity

\section{Introduction}

Non-destructive testing methods (NDT) are essential tools in estimating concrete properties (mechanical or physical). A comprehensive analysis of the mechanical properties is useful in the process of structural optimization, as well as in terms of budget efficiency.

In the case of Reinforced Concrete (RC) structures, one of the key properties is the compressive strength. An investigation from this point of view can provide an overview of the structural integrity of a building. Such an analysis helps civil engineers in optimizing the process of structural intervention by deepening the understanding of how the building works from the structural point of view and also considering the concrete mix design and 
the associated physical, mechanical, and durability characteristics. Therefore, the interventions can be targeted on those elements that have a deficient behavior, which can induce negative effects into the structure [1-7].

Traditionally, the concrete compressive strength is determined through destructive testing (DT) which is considered the most reliable testing, and thus been referred to as the reference method. In DT, there are identified three possible situations:

- The samples are prepared and tested in the laboratory;

- The samples are collected on the construction site during the concrete casting, followed by curing and testing in the laboratory;

- The concrete cores are extracted directly from the structure (specific elements) and, after specific processing and conditioning, they are tested in the laboratory.

In the first situation, this testing is performed in order to evaluate or calibrate different mixing sequences of concrete mixture [8,9]. The samples collected on the construction site during the concrete casting are usually considered in cases of new buildings, to assess and confirm the concrete class [10] or to check compressive strength at intermediate specific terms (identity tests at 1 day, 2 days, 7 days, etc.). In the case of existing buildings, DT is performed by extracting concrete cores from certain concrete elements, such as columns, beams, slabs, diaphragms, etc., and then subjecting them to a compressive load until failure [11]. The preparation of the cores is made with respect to specific regulations and procedures in order to ensure the necessary testing accuracy [12].

According to $[13,14]$ the analysis procedure depends on the amount of available information regarding the existing structure to be evaluated: information about the construction geometry, elements detailing, and material type determine the appropriate Knowledge Level (KL) of the structure under study. There are considered to be three KLs, defined as follows: KL1-limited, KL2-normal, and KL3-full, and to each of them is assigned a Confidence Factor (CF): $\left(\mathrm{CF}_{\mathrm{KL} 1}=1.35 ; \mathrm{CF}_{\mathrm{KL} 2}=1.20\right.$; and $\left.\mathrm{CF}_{\mathrm{KL} 3}=1.00\right)$. The confidence factor is used as a correction factor for incomplete knowledge and level of uncertainty [11]. To reach a superior level of confidence (KL3 level, for instance), a large number of cores must be extracted from the structure, which can cause several inconveniences such as they can be time- and resource-consuming and also affect the structure itself due to specimens' extraction. Furthermore, the compressive strength may vary within the same element, due to the specific heterogeneity of concrete [15].

NDT represents a possible, viable alternative, mainly in terms of cost efficiency and also as they are fast in delivering results. However, NDT techniques measure indicators that are sensitive to a specific concrete property. For example, the ultrasonic pulse velocity and rebound hammer are sensitive to mechanical properties such as the compressive strength and porosity of concrete [16]. Another major problem pointed out by Angst [17] is the fact that the relation between mechanical properties and measured indicators is not constant. This is attributed to several causes, strongly connected to concrete physical characteristics (its specific heterogeneity, the porosity, water content, aggregate maximum dimension, etc.) and also to element exposure, measured data accuracy, and limited number of measurements.

Over the years, several NDT methods have been developed with the main purpose of estimating, as correctly as possible, the mechanical properties of materials and elements. A short overview of the NDT methods used on concrete structures is presented thus:

- One of the first and most used NDTs is the visual inspection (VI) [18]. It focuses on identifying visible pathologies in concrete such as cracks, voids, and spalling and trying to understand what caused them. It is a subjective and limited method, as internal characteristics of the structure cannot be determined, but it is also an important first step for further evaluation, providing useful information for establishing optimum and adequate methodologies (DT or NDT) for further investigation.

- The rebound hammer (RHS) determines the surface hardness. The main advantages are the fact that is a simple to use method with low cost and energy. The method tests 
the concrete strength on a depth of $2-3 \mathrm{~cm}$, this being the reason why it should be combined with other methods that tests the concrete elements in depth [19].

- The radiographic testing (RT) consists of a radioactive isotope source that transmits photons continuously through the concrete element, photons which are developed on a radiation sensitive film. It is mainly used for visualizing interior features of an element. There are many types of radiography that each have a specific application. In order to detect voids, cracks, or other interior defects, gamma-ray radiography was found to be useful [20]. This method is rarely used due to safety concerns.

- The carbonatation testing (CT) is made by spraying an exposed surface of the concrete element with a solution containing $1 \%$ phenolphthalein. The calcium hydroxide reacts with the solution resulting in a pink color, while the carbonated area will remain uncolored [21].

- Infrared thermography (IT) is used in order to determine the internal voids, cracks, or delamination by measuring the time delay before the temperature changes [22].

- The electromagnetic and radar testing (E\&RT) are the most used NDT methods for the identification of reinforcements position, diameter, and distance from the surface [23].

- The drilling resistance method (DRM) presumes estimating the concrete compressive strength by counting the time required to drill a certain distance in the concrete element with a constant force and rotation speed. Serkan et al. [24] proved the accuracy of the method and presented good results when it was combined with the rebound hammer testing.

- Ultrasonic pulse velocity (UPV) is an NDT which has been extensively investigated for decades [25]. The method consists of measuring the transit time of an ultrasonic pulse from a transmitter to a receiver, knowing the distance between the two transducers. A short amount of time is needed for the ultrasonic pulse to pass through an element result in a high velocity, meaning a compact and homogenous material. This is an indication of the element's strength.

The most used NDT methods, for estimating concrete compressive strength, are the Schmidt rebound hammer, the ultrasonic pulse velocity, and the sonic rebound (SonReb) which consists of a combination of the first two methods. Făcăoaru et al. [26] developed and described the procedure which consists of applying some correctional factors based on cement type and dosage, granulometry and type of aggregates, and concrete age. SonReb has a high degree of efficiency and is still used worldwide, successfully, in estimating concrete compressive strength. Still, one of the most important disadvantages of the method is its requirements of mix design information regarding the evaluated concrete; in the case of older structures this information is not always available, which may lead to unprecise results. The viability of the method should also be verified on various types of concrete mix design developed with different additions, waste, or by-products (mineral, rubber, plastic, glass, etc.), which gained large diversity in recent years due to environmental protection requirements and Circular Economy implementation [2-4].

Researchers tried to develop various relationships between the measured indicators and the mechanical properties of concrete, by using different techniques, such as response surface (RS) [27-34], data fusion (DF) [35-37], and artificial neural networks (ANN) [38-43]. The empirical relationships developed over the years have a different structure: linear (LN) [40,41], polynomial (PL) [44,45], and power (PW) [46,47]. Sbartai et al. [34] report a satisfactory level in predicting concrete properties based on ultrasonic pulse velocity, ground penetration radar (GPR), electrical resistivity measurements, and data interpretation through the means of the response surface. However, when the data is interpreted with the help of ANN, the results have a higher rate of predictability. Asteris et al. [40] developed and optimized an ANN that considers the ultrasonic pulse velocity and Schmidt rebound hammer as the input values needed in order to estimate the concrete compressive strength. Based on the statistical parameters employed to evaluate the performance, the developed ANN model proved to have high efficiency in estimating the compressive strength, both when applied on its own database and also applied on other databases of 
different researchers. Khademi et al. [41] compared different techniques used to predict the 28 days compressive strength of concrete. In their mentioned study, a multiple linear regression (MLR), an artificial neural network, and adaptive neuro-fuzzy inference system models (ANFIS) were implemented with the purpose of finding the most accurate method of estimating concrete compressive strength. It was concluded that both ANN and ANFIS models can predict the concrete compressive strength more accurately than MLR, which proved to be unreliable. This is due to the fact that these models consider the non-linear correlation between the variables used as input data. It was also concluded that the accuracy of prediction is influenced by the number of input variables.

Breysse concluded [16] that a universal law between NDT and concrete compressive strength does not exist, despite the fact that many authors tried to find one.

This paper aims to present a methodology in estimating the concrete compressive strength by using ultrasonic pulse velocity as the only on-site testing method and a series of mathematical relations connecting the UPV with the moduli of elasticity (dynamic and static) and finally with the compressive strength.

\section{Materials and Methods}

\subsection{The Destructive Method (DT)}

This method is considered to deliver the most reliable results regarding the concrete compressive strength and, in this study, all results are reported to this method, considered to be the reference one. Consequently, the precision rate of the proposed method is also established with respect to the DT, as reference base of evaluation. DT consists of extracting concrete cores from the existing elements, cores which are then subjected to a series of laboratory processing and conditioning after which they are subjected to compression load until failure. The resulting compressive bearing capacity $\left(\mathrm{f}_{\mathrm{car}}\right)$ is corrected by a series of coefficients described in Equation (1) provided by Romanian Norm NP 137 [12], thus resulting in the equivalent concrete compressive strength $\left(\mathrm{f}_{\mathrm{is}}\right)$.

$$
f_{\text {is }}=a \cdot b \cdot c \cdot e \cdot g \cdot d \cdot f_{c a r}
$$

where: $\mathrm{f}_{\text {is }}$-equivalent concrete compressive strength (MPa); a-coefficient that takes into account the influence of the core diameter; $b$-coefficient that takes into account the height/diameter ratio; c-coefficient that takes into account the influence of the degraded layer; e-coefficient that takes into account the nature of the leveling layer; g-coefficient that takes into account the humidity of the concrete core; $d$-coefficient that takes into account the position and diameter of the reinforcement bars; and $\mathrm{f}_{\text {car }}$-resulted compressive bearing capacity (MPa).

As mentioned in the previous paragraph, destructive testing inflicts damage on the tested element; therefore, the number of cores must be maintained to a minimum in order to preserve the structural integrity of the element. For this reason, it is possible that the obtained values, calculated on an insufficient number of specimens, namely extracted cores from a designated element or assembly, do not reflect the overall value of the compressive strength of the targeted element. Additionally, in some cases, the extraction of the concrete core itself can prove to be difficult or even impossible to perform due to technological conditions such as the position of the designated element in the structure, the possibility to fix the drilling machine in order to extract the concrete core, etc.

\subsection{Ultrasonic Pulse Velocity (UPV)}

The ultrasonic pulse velocity was used as the on-site NDT testing method. In accordance with the theory of sound propagation in solids, the velocity of the ultrasonic signal depends on the density and elastic modulus of the material subjected to testing [48].

A calibration between compressive strength and ultrasonic pulse velocity for each concrete sample assures enough dependability for the two indicators [49]. Naik et al. [50] 
presented a full review of the method. ultrasonic pulse velocity can be determined with Equation (2) presented by Romanian Norm NP 137 [12].

$$
\mathrm{V}_{\mathrm{L}}=\mathrm{L} / \mathrm{T}
$$

where: $\mathrm{V}_{\mathrm{L}}$-ultrasonic pulse velocity $(\mathrm{km} / \mathrm{s}) ; \mathrm{L}$ - path length in concrete $(\mathrm{mm})$; and $\mathrm{T}$ transit time $(\mu \mathrm{s})$.

\subsection{Theoretical Considerations}

Modulus of elasticity of concrete $(\mathrm{E})$ is a property of concrete that estimates the potential deformation of a structural element under service conditions [51]. The factors influencing this property are the dosage of cement, concrete age and class, the binder characteristics, and proportions.

The static modulus of elasticity $\left(\mathrm{E}_{\mathrm{s}}\right)$ is a fundamental parameter that is defined by the stress-strain diagram under static loads [51] and it is generally estimated based on design code, not on direct measurements.

The dynamic modulus of elasticity $\left(E_{d}\right)$, in comparison to $E_{s}$, is defined by the ratio of stress-strain under vibratory conditions [52]. The most common techniques for determining $E_{d}$ are resonance frequency or UPV [53], but a study conducted by Luo and Bungey [54] presented a new approach by using surface waves in order to determine $E_{d}$. For this study, $\mathrm{E}_{\mathrm{d}}$ was determined accordingly to Romanian Guide GE 039 [55] via UPV using Equation (3).

$$
\mathrm{E}_{\mathrm{d}}=\frac{\left(1+\Theta_{\mathrm{d}}\right) \cdot\left(1-2 \cdot \Theta_{\mathrm{d}}\right)}{1-\Theta_{\mathrm{d}}} \cdot \frac{\gamma}{\mathrm{g}} \cdot \mathrm{V}_{\mathrm{L}}^{2}
$$

where: $E_{d}$-dynamic modulus of elasticity (MPa); $\Theta_{d}$-dynamic Poisson's ratio; $\gamma$-air dry density $\left(\mathrm{kg} / \mathrm{m}^{3}\right) ; \mathrm{g}$-gravitational acceleration $\left(\mathrm{m} / \mathrm{s}^{2}\right)$; and $\mathrm{V}_{\mathrm{L}}$ - ultrasonic pulse velocity $(\mathrm{km} / \mathrm{s})$.

Romanian Guide GE 039 [55] presents a mathematical expression, Equation (4), for the determination of the dynamic Poisson's ratio, but for this study, the dynamic modulus of elasticity was assumed the value presented by the technical literature [55], namely $\Theta_{\mathrm{d}}=0.25$ (for concrete preserved in the air).

$$
\Theta_{\mathrm{d}}=\frac{(2 \cdot \mathrm{n} \cdot 1)^{2}}{\mathrm{~V}_{\mathrm{L}}^{2}}
$$

where: $\mathrm{n}$-fundamental resonant frequency (cycles/sec); l-length of specimen (m); and $\mathrm{V}_{\mathrm{L}}$-ultrasonic pulse velocity $(\mathrm{km} / \mathrm{s})$.

Thereby, when considering the $\Theta_{d}=0.25$ the values of the function depending on the dynamic Poisson's ratio becomes:

$$
f\left(\Theta_{d}\right)=\frac{\left(1+\Theta_{d}\right) \cdot\left(1-2 \cdot \Theta_{d}\right)}{1-\Theta_{d}}=0.83
$$

Inserting Equation (5) in Equation (3) results the dynamic modulus of elasticity has the following expression:

$$
\mathrm{E}_{\mathrm{d}}=0.83 \cdot \frac{\gamma}{\mathrm{g}} \cdot \mathrm{V}_{\mathrm{L}}^{2}
$$

Regarding the air-dry density Salman [56] and Panzera et al. [57] conducted studies to find a linear correlation between air-dry density $(\gamma)$ and UPV. In this study, Equation (7), presented by Salman [56] was used to determine the air-dry density of concrete.

$$
\gamma=114.8 \cdot \mathrm{V}_{\mathrm{L}}+1813
$$

where: $\gamma$-air-dry density $\left(\mathrm{kg} / \mathrm{m}^{3}\right)$ and $\mathrm{V}_{\mathrm{L}}$-ultrasonic pulse velocity $(\mathrm{km} / \mathrm{s})$. 
In order to establish the accuracy of the proposed equation, the air-dry density of concrete was experimentally determined. The samples were weighed and measured with the purpose of determining the apparent volume. Comparing the mean values of air-dry density obtained experimentally $\left(\gamma_{\mathrm{e}}\right)$ with the mean values of the predicted ones using Equation $(7)\left(\gamma_{t}\right)$, it was shown it reached a precision rate of $98 \%$.

Furthermore, the theoretical air-dry density was used in this study as it was proven to be efficient, thus the method remained completely non-destructive and depended only on UPV.

Romanian Guide GE 039 [55] stipulates that the ratio between $E_{s}$ and $E_{d}$ ranges, in general, between $0.85-0.95$. For this study, the correlation between the two moduli of elasticity was determined by experimentally. Therefore, each modulus of elasticity $\left(E_{s}\right.$ and $\left.E_{d}\right)$ was calculated individually and then a direct link between them was established. $E_{d}$ was determined via UPV (Equation (6)) and $\mathrm{E}_{\mathrm{s}}$ was determined via DT (Equation (8)).

For determining the static modulus of elasticity, with the air-dry density determined with Equation (7) and compressive strength obtained destructively $\left(f_{i s}\right)$ determined with Equation (1), using the mathematical relationship presented by Noguchi et al. [51] (Equation (8)), a static modulus of elasticity could be determined.

$$
\mathrm{E}_{\mathrm{s}}=2.1 \cdot 10^{5} \cdot\left(\frac{\gamma}{2.3}\right)^{1.5} \cdot\left(\mathrm{f}_{\mathrm{c}} / 200\right)^{1 / 2}
$$

where: $E_{s}$-static modulus of elasticity $(\mathrm{MPa}) ; \mathrm{f}_{\mathrm{c}}=\mathrm{f}_{\mathrm{is}}$-concrete strength (MPa); and $\gamma=\gamma_{\mathrm{t}}$-concrete air-dry density determined via UPV $\left(\mathrm{kg} / \mathrm{m}^{3}\right)$.

The dynamic modulus of elasticity was mathematically calculated with Equation (6), using the ultrasonic pulse velocity.

Comparing the values of the two moduli of elasticity, determined for each specimen separately, it was established a direct and linear link between them described in Equation (9).

$$
\mathrm{E}_{\mathrm{s}}=0.75 \cdot \mathrm{E}_{\mathrm{d}}
$$

Using Equation (9), the static modulus of elasticity can now be determined only from the ultrasonic pulse velocity measurements and using Equation (7) the air-dry density can be obtained through the same measurements. Therefore, in Equation (8) the only unknown parameter remains concrete compressive strength $\left(f_{c}\right)$. Extracting that parameter and rewriting Equation (8) results in a relationship (Equation (10)) where the compressive strength value depends only on parameters that can be determined via UPV.

$$
\mathrm{f}_{\mathrm{c}}=\left(\mathrm{E}_{\mathrm{s}}^{2} \cdot 200\right) \cdot\left[2.1 \cdot 10^{5} \cdot(\gamma / 2.3)^{1.5}\right]^{2}
$$

\subsection{Experimental Procedure}

The study was conducted on 90 concrete cores with a diameter of 74 and $94 \mathrm{~mm}$, extracted from different elements of different structures (Figure 1). The elements include the raft foundation, columns, beams, and reinforced concrete walls. After the extractions of the cores, the processing was conducted in accordance with Romanian Norm NP 137 [12]. The specimens were cut at both ends with a wet diamond disk and then dry air stored in laboratory conditions T: $(21 \pm 3){ }^{\circ} \mathrm{C}$ and $\mathrm{RH}:(50 \pm 5) \%$, in accordance to Romanian Norm NP 137 [12]. The core specimens were cured for five days before weighting and UPV testing. This conditioning was performed to avoid that the humidity resulting from the wet cutting would affect the UPV data. Figure 1 presents the concrete sample after specific cutting and conditioning and before the destructive testing. 


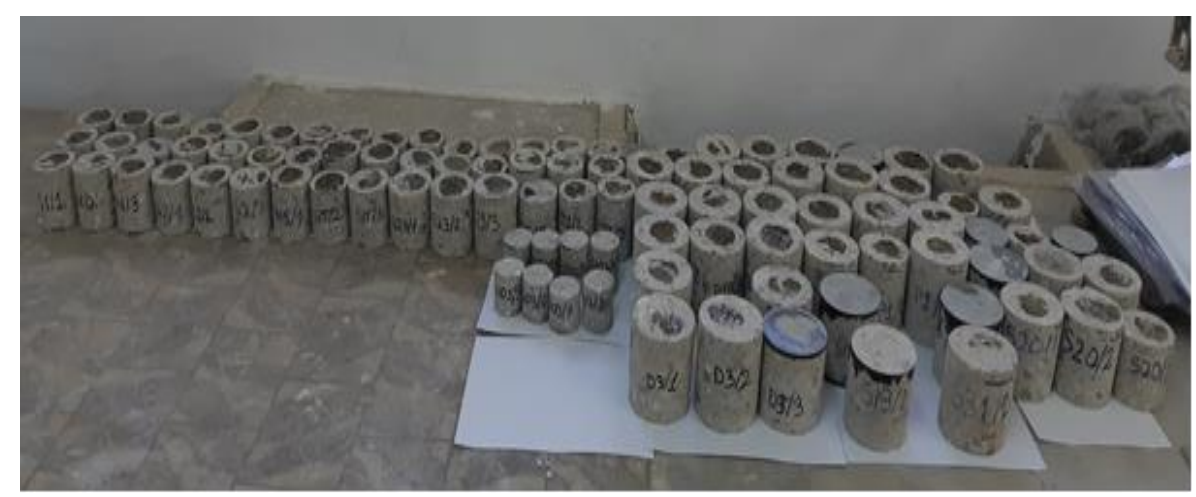

Figure 1. Concrete core specimens.

The as-received state density was determined with respect to SR EN 12390-7 [58] by specimens air-dry curing and then their measuring (diameter and height, for volume calculation), followed by their weighting. Then, the specimens were tested via UPV with a Tico Proceq device equipped with $54 \mathrm{kHz}$ transducers (Figure 2). The coupling agent for the transducers was Vaseline. The last step was testing destructively the specimens, in compression. This procedure was conducted with respect to SR EN 12390-3 [59] which stipulates the curing and the testing conditions: the recommended dimensions of the concrete cores, the air-dry exposure, the preparation, and positioning, etc., as well as the loading rate. The destructive testing was conducted with a hydraulic press at a loading rate of $0.6 \mathrm{MPa} / \mathrm{s}$.

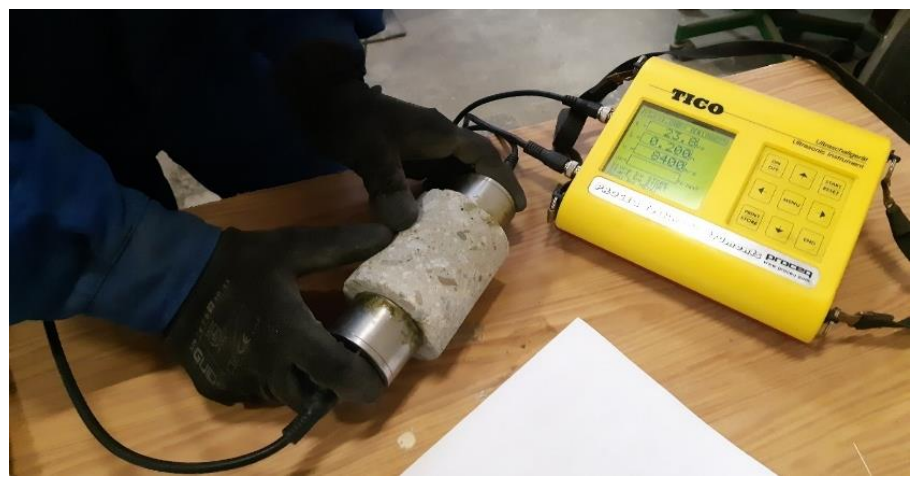

Figure 2. UPV testing.

Figure 3 presents the flowchart of the proposed method, consisting of the sequence of the major considered steps, in terms of experimental testing (black curve contour) and the corresponding parameters (light blue contour) determined by using the previously collected data.

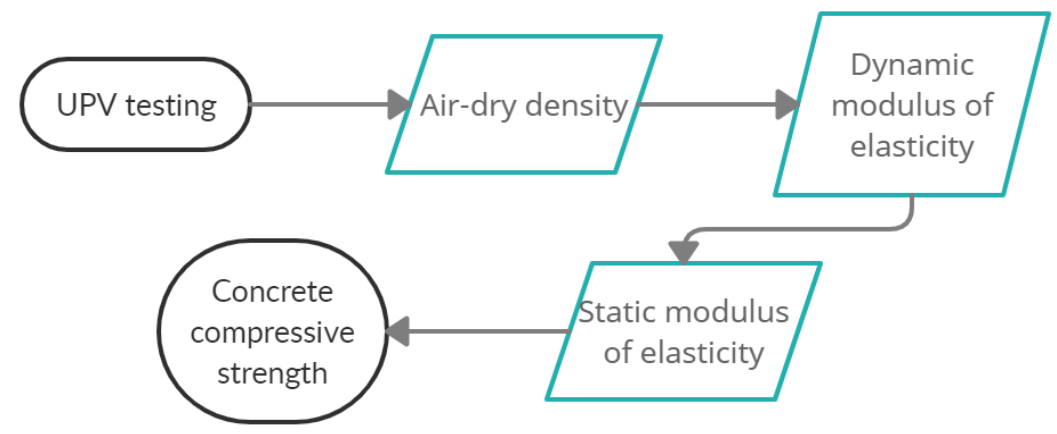

Figure 3. Flowchart of the presented method. 


\section{Results and Discussions}

\subsection{Proposed Method Compared to DT}

For a more accessible interpretation of the results, the core specimens were divided into four groups. The considered division criterion is the value of compressive strength $\left(\mathrm{f}_{\mathrm{is}}\right)$ determined via the Destructive Method, as follows:

- Group 1 [15-20) MPa: $\mathrm{f}_{\text {is }}$ ranges from 15 to $20 \mathrm{Mpa}$;

- Group 2 [20-25) Mpa: $\mathrm{f}_{\text {is }}$ ranges from 20 to $25 \mathrm{Mpa}$;

- Group 3 [25-30) Mpa: $\mathrm{f}_{\text {is }}$ ranges from 25 to $30 \mathrm{Mpa}$;

- Group $4 \geq 30 \mathrm{MPa}: \mathrm{f}_{\mathrm{is}}$ exceeds $30 \mathrm{MPa}$.

The theoretical methods for assessing the concrete air-dry density and compressive strength, for the four considered groups of specimens, were statistically evaluated with respect to the experimental and reference procedures, in terms of coefficient of variation $(\mathrm{CoV})$, and also the accuracy $\left(\mathrm{A}_{\mathrm{c}}\right)$.

$\mathrm{CoV}$ is defined by Everitt [60] by the means of Equation (11), as the ratio between the standard deviation $(\sigma)$ and the mean value $(\mu)$ of the group of specimens where applied.

$$
\mathrm{CoV}=\frac{\sigma}{\mu}
$$

where: $\mathrm{CoV}-$ coefficient of variation (\%); $\sigma$-standard deviation; and $\mu-$ mean value.

The air-dry density and compressive strength (measured and predicted) were also analyzed in terms of accuracy, defined in accordance with ISO 5725-1 [61] as the ratio between the predicted value (result of the proposed method) and the "true" value, provided by the reference method. Accuracy was calculated by the use of Equation (12).

$$
A_{c}=\frac{\text { Predicted value }}{\text { Measured value }} \cdot 100
$$

where: $A_{c}$-accuracy (\%).

Table 1 presents the air-dry density values for each of the four specimen groups, determined by using both methods: the experimental method, (comprises specimens' measurement and weighing) and the Salman theoretical method (based on UPV individual values) [56]. The accuracy was calculated by using as input data the mean values recorded for each of the four groups of core specimens.

Table 1. Air-dry density.

\begin{tabular}{ccccccccccc}
\hline \multicolumn{10}{c}{ Density $\left(\mathbf{k g} / \mathbf{m}^{3}\right)$} \\
\hline & Min & Mean & Max & CoV (\%) & Min & Mean & Max & CoV (\%) & $\begin{array}{c}\text { Accuracy } \\
(\%)\end{array}$ \\
\hline $\begin{array}{c}\text { Group 1 } \\
{[15-20) \text { MPa }}\end{array}$ & 2149 & 2237 & 2319 & 1.7 & 2215 & 2236 & 2254 & 0.4 & 99 \\
\hline $\begin{array}{c}\text { Group 2 } \\
{[20-25) \text { MPa }}\end{array}$ & 2210 & 2300 & 2384 & 2.1 & 2241 & 2263 & 2286 & 0.5 & 98 \\
\hline $\begin{array}{c}\text { Group 3 } \\
{[25-30) \text { MPa }}\end{array}$ & 2221 & 2317 & 2411 & 2.7 & 2259 & 2286 & 2347 & 0.8 & 98 \\
\hline $\begin{array}{c}\text { Group 4 } \\
\geq 30 \text { MPa }\end{array}$ & 2256 & 2312 & 2365 & 1.3 & 2281 & 2308 & 2322 & 0.6 & 99 \\
\hline
\end{tabular}

Figures 4 and 5 present a graphical representation of the mean values and accuracy of measured and predicted density. With an accuracy ranging between $98 \%$ and $99 \%$, the theoretical Salman method [56] for determining the density via UPV testing proves to be a viable approach. This conclusion is also supported by the CoV values, ranging from $1.3 \%$ to $2.7 \%$ for the reference method (experimental measurements) and presenting 
a more compact range of smaller $\mathrm{CoV}$ values, from $0.4 \%$ to $0.8 \%$, for the theoretical, Salman approach.

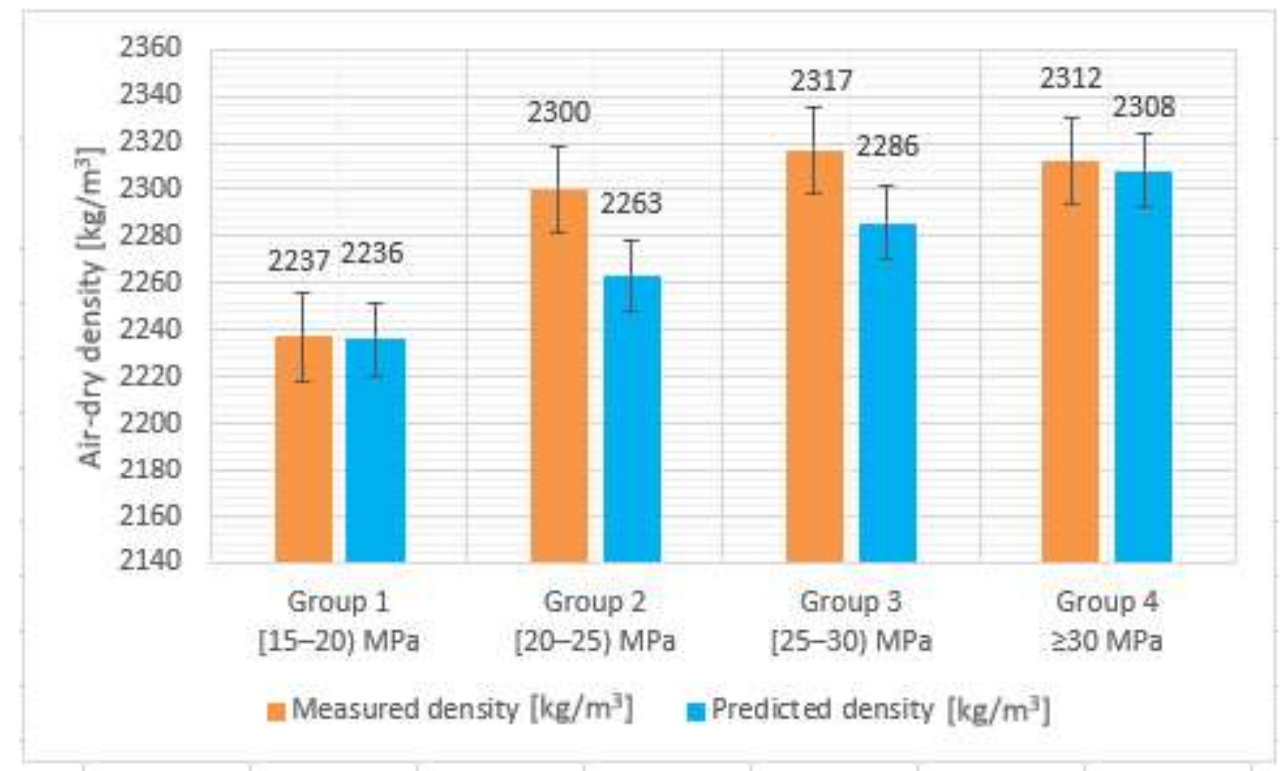

Figure 4. Air-dry density, mean values.

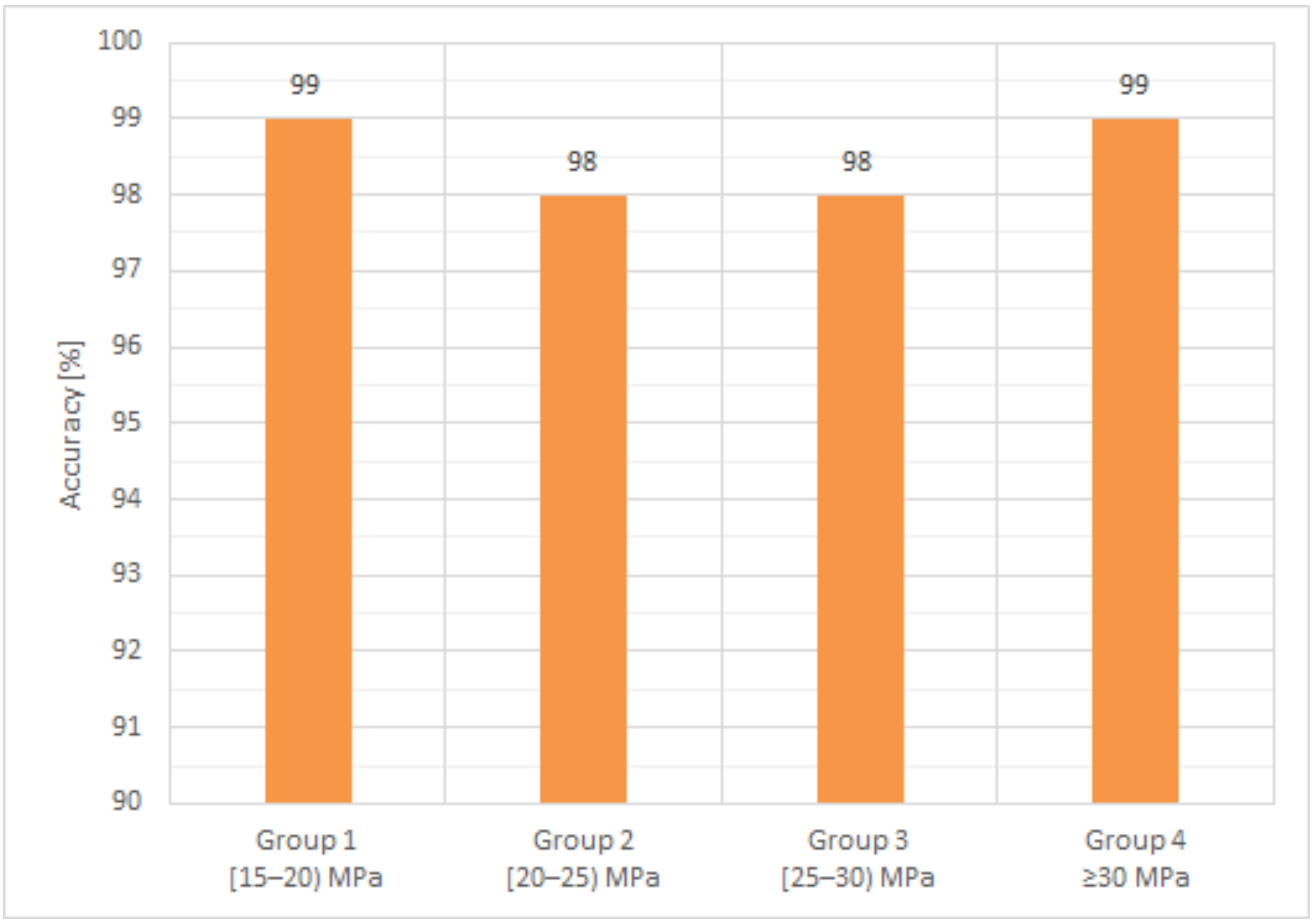

Figure 5. Air-dry density, the accuracy of the NDT method with respect to the reference.

Table 2 presents the results of compressive strength for each of the four core groups, determined by both methods: the proposed method (UPV testing and interpretation via moduli of elasticity) and the reference, destructive testing. 
Table 2. Compressive strength.

\begin{tabular}{|c|c|c|c|c|c|c|c|c|c|}
\hline \multicolumn{10}{|c|}{ Compressive Strength (MPa) } \\
\hline & \multicolumn{4}{|c|}{ DT Compressive Strength $\left(f_{i s}\right)$} & \multicolumn{4}{|c|}{ NDT Compressive Strength $\left(f_{c}\right)$} & \multirow{2}{*}{$\begin{array}{c}\text { Accuracy } \\
(\%)\end{array}$} \\
\hline & Min & Mean & Max & $\operatorname{CoV}(\%)$ & Min & Mean & Max & $\operatorname{CoV}(\%)$ & \\
\hline $\begin{array}{c}\text { Group } 1 \\
{[15-20) \mathrm{MPa}}\end{array}$ & 15.8 & 17.9 & 20.0 & 6.8 & 15.1 & 18.4 & 21.6 & 8.9 & 94 \\
\hline $\begin{array}{c}\text { Group } 2 \\
{[20-25) \mathrm{MPa}}\end{array}$ & 18.3 & 22.6 & 25.0 & 7.1 & 19.1 & 23.2 & 27.9 & 9.6 & 93 \\
\hline $\begin{array}{c}\text { Group } 3 \\
{[25-30) \mathrm{MPa}}\end{array}$ & 25.1 & 27.4 & 29.6 & 4.7 & 22.4 & 27.4 & 30.7 & 7.7 & 94 \\
\hline $\begin{array}{c}\text { Group } 4 \\
\geq 30 \mathrm{MPa}\end{array}$ & 30.2 & 33.0 & 38.9 & 6.3 & 26.9 & 33.3 & 37.0 & 10 & 94 \\
\hline
\end{tabular}

In terms of compressive strength, which is the main focus of the study, a graphical representation of the mean values and accuracy for each of the four groups is presented in Figures 6 and 7. The specimens sorting into four distinct groups function of the compressive strength, as previously specified, was considered proper for a better understanding of the phenomenon and to facilitate the data processing and the scattering of results. The wide range of values for the DT compressive strength $\left(f_{i s}\right)$ can be noted, with a minimum of 15.8 $\mathrm{MPa}$ and a maximum of $38.9 \mathrm{MPa}$. Additionally, the corresponding values for the NDT testing $\left(\mathrm{f}_{\mathrm{c}}\right)$ range from 15.1 MPa to $37.0 \mathrm{MPa}$ (Table 2).

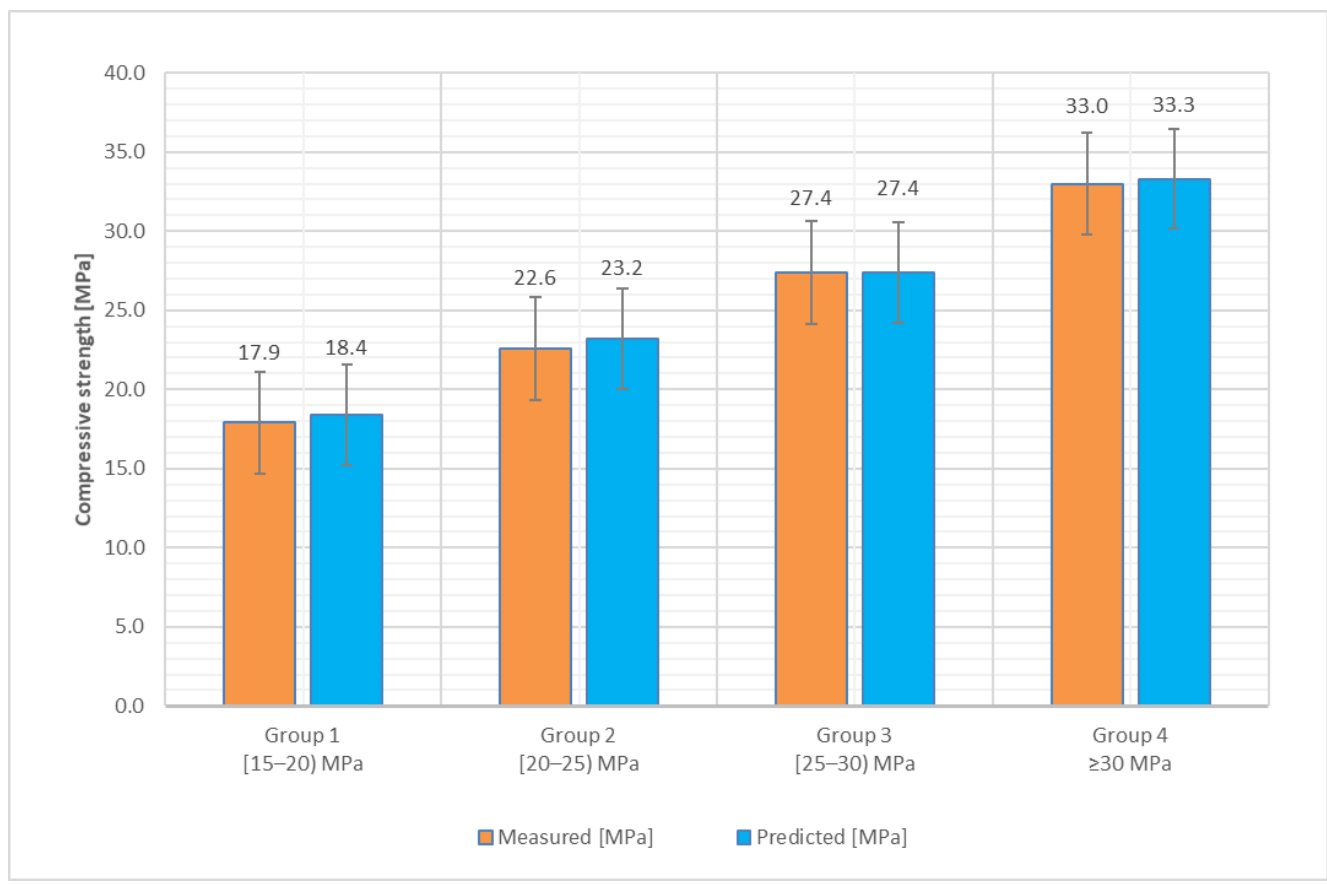

Figure 6. Compressive strength, mean values.

The accuracy of the proposed method for compressive strength determination via UPV and moduli of elasticity was also calculated using Equation (12), with respect to the mean values for each of the four groups of core specimens, presented in Table 2. The obtained results proved to be satisfactory, as the variation is very small with respect to the DT, regardless of the wide range of values. This conclusion is also supported by the $\mathrm{CoV}$ values (Table 2), ranging from 4.7 to $6.8 \%$ for the reference method and offering a similar compact range of values from 7.7 to $10 \%$ for the proposed method. 


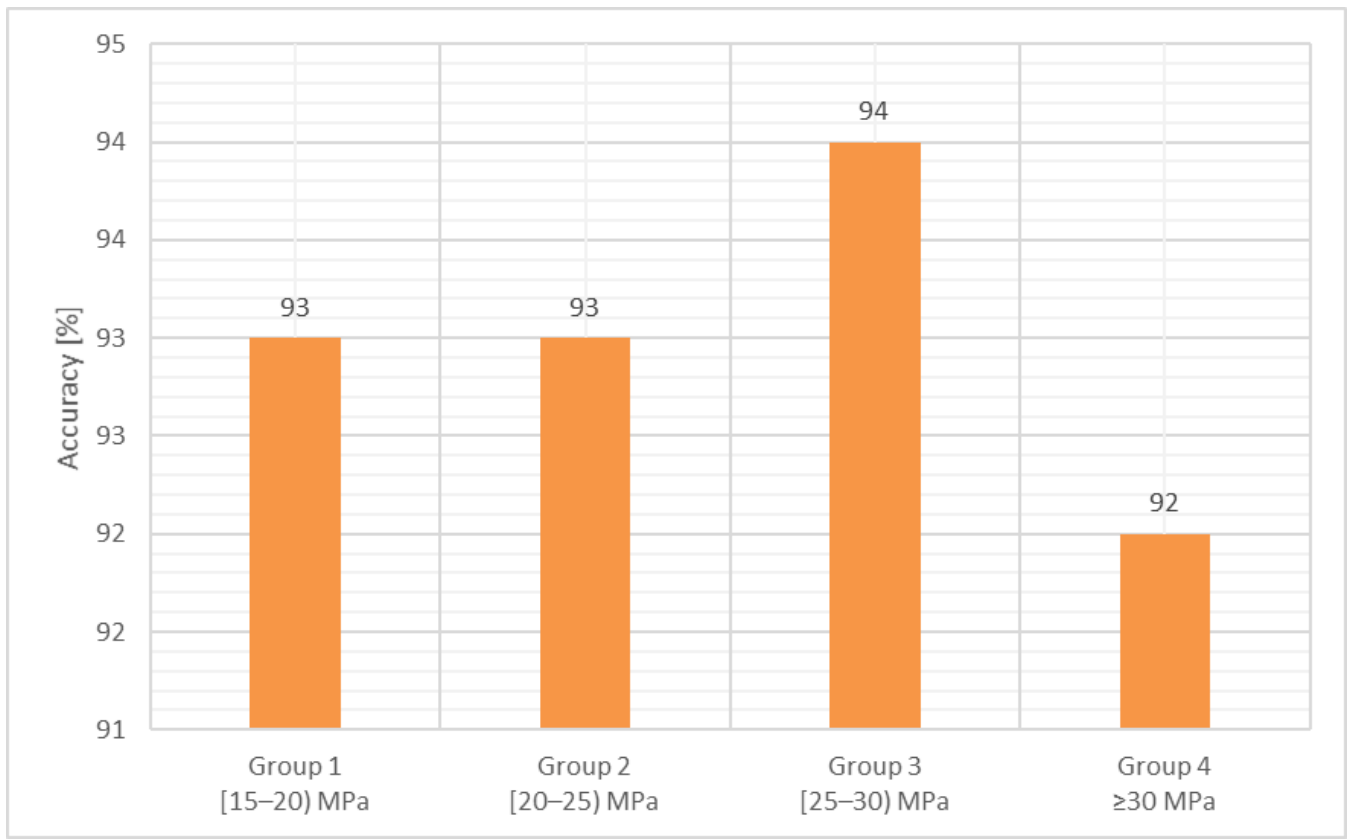

Figure 7. Compressive strength, the accuracy of the proposed method related to the reference.

Furthermore, when analyzing each group, it can be noticed that for groups 1, 2, and 4, the theoretical compressive strength, evaluated via the proposed method, tends to be a little overestimated with respect to the reference $(2.8,2.7$ and $0.9 \%$, respectively), while in the third group there is a clear match of the values.

Figure 7 graphically presents the accuracy evaluation, in terms of mean values. It can be noticed that the values are ranging from 93 to $94 \%$.

As presented in Figure 7, the precision of this method in terms of Ac reaches 93\% for the first two groups, $94 \%$ for the third group, and $92 \%$ for the fourth group. Considering all the values, the mean value of the precision is up to $93 \%$.

Figure 8 presents a graphical representation of the correlation between experimentally determined compressive strength $\left(f_{i s}\right)$ and predicted compressive strength $\left(f_{c}\right)$ is presented.

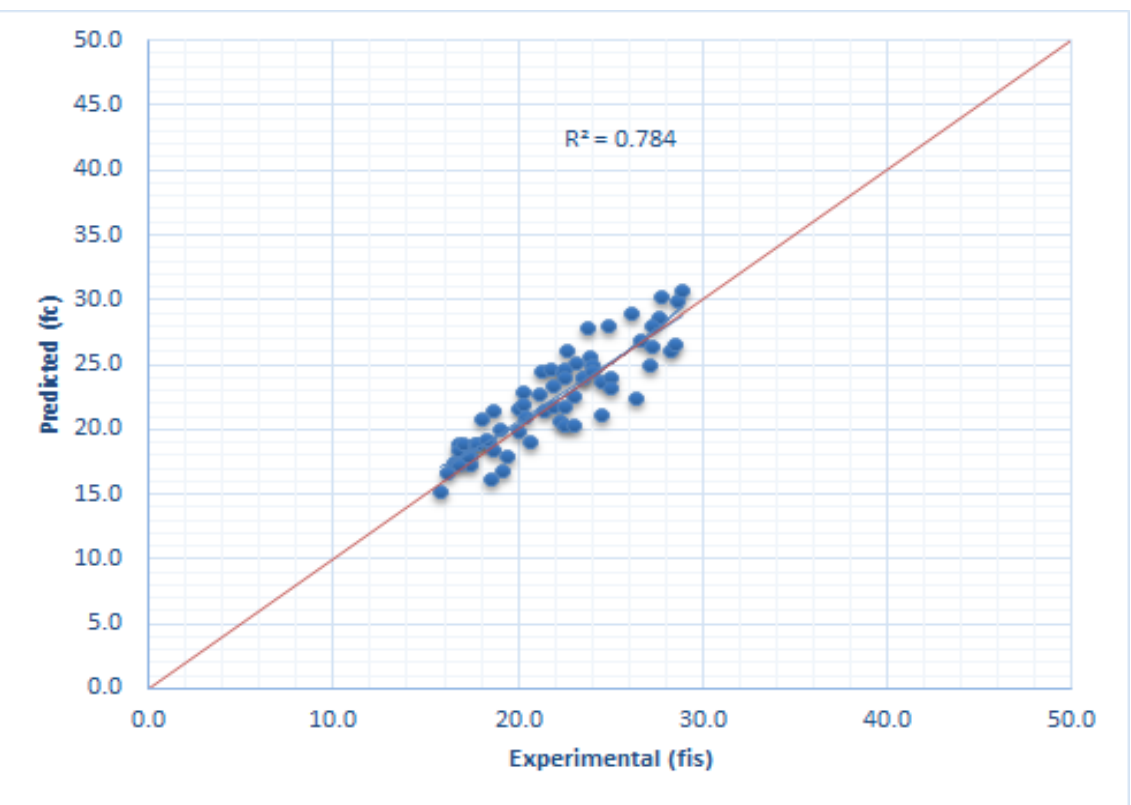

Figure 8. Correlation between experimental and calculated compressive strength. 
A good correlation is achieved between the two sets of values. The coefficient of determination $\mathrm{r}^{2}$, which is a statistical indicator of the quality of the theoretical model, is in this case equal to 0.78 .

\subsection{Proposed Method and SonReb Method Compared to Destructive Method}

For a better validation of the proposed method, the obtained results are compared to both the SonReb method and the DT. For the SonReb method, six structural elements (columns) were investigated on-site by using ultrasonic pulse velocity and Rebound Hammer Schmidt. Each element was tested in three sections, with five UPV and nine RHS measurements/section. In Table 3, the resulting mean values of the UPV, RHS, and compressive strength from each method are presented.

Table 3. The results obtained from each presented method.

\begin{tabular}{lccccc}
\hline \multirow{2}{*}{ Element } & \multirow{2}{*}{$\begin{array}{c}\text { Mean UPV } \\
\text { (km/s) }\end{array}$} & $\begin{array}{c}\text { Mean RHS } \\
\text { (div) }\end{array}$ & & \multicolumn{2}{c}{ Mean Concrete Compressive Strength } \\
\cline { 4 - 6 } & & 40 & 26.1 & 25.7 & 26.7 \\
Column 1 & 4.324 & 37 & 28.6 & 21.8 & 27.7 \\
Column 2 & 4.142 & 38 & 24.7 & 19.7 & 22.5 \\
Column 3 & 3.985 & 41 & 18.9 & 17.4 & 17.7 \\
Column 4 & 3.716 & 35 & 17.3 & 11.4 & 17.4 \\
Column 5 & 3.632 & 35 & 19.7 & 12.9 & 20.0 \\
Column 6 & 3.758 & & & & SonReb \\
\hline
\end{tabular}

A graphical representation of the accuracy is presented in Figure 9, namely a comparative analysis between the proposed method vs. SonReb method, both of them evaluated with respect to the reference, namely, the destructive method.

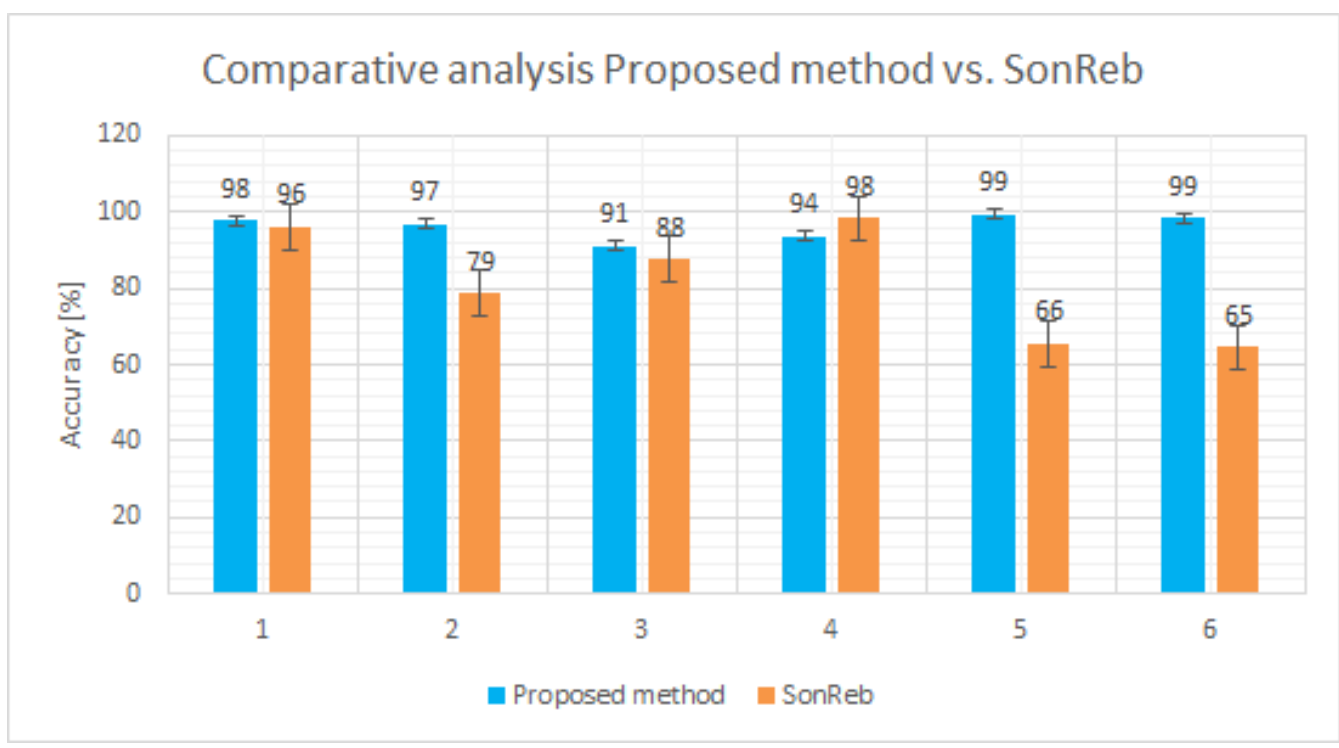

Figure 9. Graphical representation of the accuracy evaluation of each method, proposed and SonReb method, with respect to the reference method (destructive testing).

For the six elements investigated through both NDT methods, the precision rate in the case of the proposed method reaches up to $96 \%$, while in the case of the SonReb method the precision reaches up to $82 \%$.

\section{Conclusions}

The aim of this paper is to present the results obtained by combining the on-site measurements of UPV and theoretical interpretation using a set of equations developed by 
different researchers linking the values of ultrasonic pulse velocity to the dynamic modulus of elasticity, static modulus of elasticity, and finally concrete compressive strength.

Estimating concrete compressive strength through this method delivered results with high accuracy, which, in this case, ranged between 84 and 100\%. It can be noticed that the high level of accuracy remains the same regardless of the range value of compressive strength, which in this study is between 15.8 and $38.9 \mathrm{MPa}$. Additionally, the coefficient of variation $(\mathrm{CoV})$ shows reduced values, ranging along compact intervals, both for the dry-air density evaluation (from 0.4 to $0.8 \%$, for the theoretical, Salman approach) and also for the compressive strength evaluation (from 7.7 to $10 \%$, for proposed method). Further investigations will also consider the methodology and statistical approach proposed by Breysse et al. [62].

As this method relies only on UPV measurements, the on-site surface preparation and testing process must be performed with a high level of precision; otherwise, the results will have a higher level of uncertainty.

In contrast to the SonReb method, the proposed one has the advantage, so far, that there is no requirement of information about the classical concrete mix design such as cement type and dosage, granulometry, and nature of aggregates. This information is often difficult to obtain, especially in the case of buildings where the concrete mix was produced on-site with no known recipe. In the SonReb method, not knowing these parameters correct can lead to errors up to $\pm 30 \%$. In this case, although the concrete mix design was known, hence all the coefficients were correctly assumed, the accuracy of the SonReb method had a lower value than the proposed method on each analyzed concrete column when compared to DT.

The current results are clearly encouraging, offering new research perspective for method optimization and further confirmation to prove its viability, especially in terms of concrete mix design diversity, which has experienced an exponential growth in the last decades. The single and multiple additions in concrete compositions, waste, or by-products generated by the industry, may induce concrete hardened state changes which lead to complex investigation in terms of overall behavior, NDT included. A preliminary approach on this area represents the on-going study of the current research.

Author Contributions: Conceptualization, B.B. and A.G.; methodology, B.B. and V.V.; validation, B.B. and V.V.; formal analysis, C.B. and D.-D.B.-N.; investigation A.G.; resources, B.B. and S.D.; data curation, D.-D.B.-N. and S.D.; writing-original draft, B.B. and C.B.; writing-review and editing, V.V. and D.-D.B.-N.; visualization, B.B. and V.V.; supervision, C.B., A.G. and S.D. All authors have read and agreed to the published version of the manuscript.

Funding: This research received no external funding.

Institutional Review Board Statement: Not applicable.

Informed Consent Statement: Not applicable.

Acknowledgments: This paper is supported by: Programme: Research for sustainable and ecological integrated solutions for space development and safety of the built environment, with advanced potential for open innovation-“ECOSMARTCONS", Programme code: PN 193304 02: "Sustainable solutions for ensuring the population health and safety within the concept of open innovation and environmental preservation", financed by the Romanian Government. Project "Entrepreneurial competences and excellence research in doctoral and postdoctoral programs-ANTREDOC", project co-funded by the European Social Fund financing agreement no. 56437/24.07.2019. The authors would like to thank Michael Grantham of Sandberg LLP, University of Leeds and Queen's University Belfast, Institute of Concrete Technology and Editorial Board of the Journal "Case Studies in Construction Materials", UK for his support and contribution in technical editing, language editing and proofreading.

Conflicts of Interest: The authors declare no conflict of interest. 


\section{References}

1. Chalangaran, N.; Farzampour, A.; Paslar, N. Nano Silica and Metakaolin Effects on the Behavior of Concrete Containing Rubber Crumbs. CivilEng 2020, 1, 264-278. [CrossRef]

2. Chalangaran, N.; Farzampour, A.; Paslar, N.; Fatemi, H. Experimental investigation of sound transmission loss in concrete containing recycled rubber crumbs. Adv. Concr. Constr. 2021, 11, 447-454.

3. Baeră, C.; Szilagyi, H.; Lăzărescu, A. Developing Fibre Engineered Cementitious Materials with Self-Healing abilities (SH-FECM) by using polyvinyl alcohol fibres and supplementary powder addition. In Proceedings of the Fib Symposium, Krakow, Poland, 27-29 May 2019.

4. $\quad$ Baeră, C.; Vasile, V.; Matei, C.; Gruin, A.; Szilagyi, H.; Perianu, I.A. Developments fo Green Cementitious Materials by Using the Abrasive Waterjet Garnet Wastes: Preliminary Studies. Adv. Mat. Res. 2021, 1164, 87-96.

5. D'Ambrisi, A.; De Stefano, M.; Tanganelli, M.; Viti, S. The Effect of Common Irregularities on the Seismic Performance of Existing RC Framed Buildings. In Seismic Behaviour and Design of Irregular and Complex Civil Structures; Springer: Dordrecht, The Netherlands, 2013; pp. 47-58.

6. De Stefano, M.; Tanganelli, M.; Viti, S. Torsional effects due to concrete strength variability in existing buildings. Earthq. Struct. 2015, 8, 379-399. [CrossRef]

7. Viti, S.; Tanganelli, M.; De Stefano, M. The concrete strength variability as source of irregularity for RC existing buildings. Geotech. Geol. Eng. 2016, 40, 149-158.

8. Chandrappa, A.K.; Biligiri, K.P. Influence of mix parameters on pore properties and modulus of pervious concrete: An application of ultrasonic pulse velocity. Mater. Struct. 2016, 49, 5255-5271. [CrossRef]

9. Cuibuş, A.; Kiss, Z.; Gorea, M. Influence of mineral additions on the physical-mechanical properties of concretes. Rev. Rom. Mater. 2014, 44, 225-235.

10. Aryal, R.; Mishra, A.K. In-Situ compressive strength assessment of concrete in under-construction residential buildings at Gaindakot municipality. Mater. Today Proc. 2020. [CrossRef]

11. Pucinotti, R. Assessment of In Situ characteristic concrete strength. Constr. Build. Mater. 2013, 44, 63-73. [CrossRef]

12. iTeh. NP 137. In Normative for In Situ Evaluation of the Concrete Compressive Strength of the Existing Constructions; iTeh: Kamen, Germany, 2014.

13. European Union. EN 1998-3. In Eurocode 8-Design of Structures for Earthquake Resistance—Part 3: Assessment and Retrofitting of Buildings; European Union: Brussels, Belgium, 2005.

14. Ministry of Development, Public Works and Administration of Romania. P100-3. Design Code_Part 3: Provisions for Seismic Assessment of Existing Buildings; M.Of., p I, nr. 1003 bis/13.12.2019; Ministry of Development, Public Works and Administration of Romania: Bucharest, Romania, 2019.

15. Masi, A.; Chiauzzi, L. An experimental study on the within-member variability of in situ concrete strength in RC building structures. Constr. Build. Mater. 2013, 47, 951-961. [CrossRef]

16. Breysse, D. Nondestructive evaluation of concrete strength: An historical review and a new perspective by combining NDT methods. Constr. Build. Mater. 2012, 33, 139-163. [CrossRef]

17. Angst, U.M.; Polder, R. Spatial variability of chloride in concrete within homogeneously exposed areas. Cem. Concr. Res. 2014, 56, 40-51. [CrossRef]

18. Zambon, I.; Vidovic, A.; Strauss, A.; Matos, J. Condition Prediction of Existing Concrete Bridges as a Combination of Visual Inspection and Analytical Models of Deterioration. Appl. Sci. 2019, 9, 148-157. [CrossRef]

19. Brencich, A.; Cassini, G.; Pera, D.; Riotto, G. Calibration and Reliability of the Rebound (Schmidt) Hammer Test. JACE 2013, 1, 66-78. [CrossRef]

20. Garney, G. Defects Found through Non-Destructive Testing Methods of Fiber Reinforced Polymeric Composites; California State University: Long Beach, CA, USA, 2006.

21. Valls, S.; Vazquez, E. Accelerated carbonatation of sewage sludge-cement-sand mortars and its environmental impact. Cem. Concr. Res. 2001, 31, 1271-1276. [CrossRef]

22. Vavilov, V.P.; Burleigh, D.D. Review of pulsed thermal NDT: Physical principles, theory and data processing. NDT E Int. 2015, 73, 28-52. [CrossRef]

23. Dobriec, L.; Jasinski, R.; Mazur, W. Accuracy of Eddy-Current and Radar Methods Used in Reinforcement Detection. Materials 2019, 12, 1168-1192.

24. Serkan, K.; Muhammet, A.; Oguz, G. Estimation of In-situ concrete strength using drilling resistance. MATEC Web Conf. Concr. Solut. 2019, 289, 06001.

25. Shariati, M.; Ramli-Sulong, N.H.; Aragnejad, K.H.M.M.; Shafigh, P.; Sinaei, H. Assessing the strength of reinforced concrete structures through Ultrasonic Pulse Velocity and Schmidt Rebound Hammer tests. Sci. Res. Essays. 2011, 6, $213-220$.

26. Făcăoaru, I. Non-Destructive Testing of Concrete in Romania. Symposium on Non-Destructive Testing of Concrete and Timber; Thomas Telford Publishing: London, UK, 1969; pp. 39-49.

27. Haque, M.; Ray, S.; Mita, A.F.; Bhattacharjee, S.; Bin Shams, M.J. Prediction and Optimization of the Fresh and Hardened Properties of Concrete Containing Rice Hush Ash and Glass Fiber Using Response Surface Methodology. Case Stud. Constr. Mater. 2021, 14, e00505. 
28. Shahmansouri, A.A.; Nematzadeh, M.; Behnood, A. Mechanical properties of GGBFS-based geopolymer concrete incorporating natural zeolite and silica fume with an optimum design using response surface method. J. Build. Eng. 2021, 36, 102138. [CrossRef]

29. Zhang, Q.; Feng, X.; Chen, X.; Lu, K. Mix design for recycled aggregate pervious concrete based on response surface methodology. Constr. Build. Mater. 2020, 259, 119776. [CrossRef]

30. Sultana, N.; Hossain, S.M.Z.; Alam, M.S.; Hashish, M.M.A.; Islam, M.S. An experimental investigation and modeling approach of response surface methodology coupled with crow search algorithm for optimizing the properties of jute fiber reinforced concrete. Constr. Build. Mater. 2020, 243, 118216. [CrossRef]

31. Awolusi, T.F.; Oke, O.L.; Akinkurolere, O.O.; Sojobi, A.O. Application of response surface methodology: Predicting and optimizing the properties of concrete containing steel fibre extracted from waste tires with limestone powder as filler. Case Stud. Constr. Mater. 2019, 10, e00212. [CrossRef]

32. Sun, Y.; Yu, R.; Shui, Z.; Wang, X.; Qian, D.; Rao, B.; Huang, J.; He, Y. Understanding the porous aggregates carrier effect on reducing autogenous shrinkage of Ultra-High Performance Concrete (UHPC) based on response surface method. Constr. Build. Mater. 2019, 222, 130-141. [CrossRef]

33. Rooholamini, H.; Hassani, A.; Aliha, M.R.M. Evaluating the effect of macro-synthetic fibre on the mechanical properties of roller-compacted concrete pavement using response surface methodology. Constr. Build. Mater. 2018, 159, 517-529. [CrossRef]

34. Sbartai, Z.M.; Laurens, S.; Elachachi, S.M.; Payan, C. Concrete properties evaluation by statistical fusion of NDT techniques. Constr. Build. Mater. 2012, 37, 943-950. [CrossRef]

35. Castanedo, F. A Review of Data Fusion Techniques. Sci. World J. 2013, 2013, 704504. [CrossRef]

36. Bloch, I. Information Combination Operators for Data Fusion: A Comparative Review with Classification. IEEE Trans. Syst. Man. 1996, 26, 52-67. [CrossRef]

37. Pollard, E. Evaluation de Situations Dynamiques Multicibles par Fusion de Donnees Spatio-Temporelles. Ph.D. Thesis, Grenoble University, Grenoble, France, 2010.

38. Yaman, M.A.; Elaty, A.; Taman, M. Predicting the ingredients of self-compacting concrete using artificial neural network. Alex. Eng. J. 2017, 56, 523-532. [CrossRef]

39. Concha, N.; Oreta, A.W. An improved prediction model for bond strength of deformed bars in RC using UPC test and Artificial Neural Network. Int. J. Geomate 2020, 18, 179-184. [CrossRef]

40. Asteris, P.G.; Mokos, V.G. Concrete compressive strength using artificial neural networks. Neural. Comput. Appl. 2020, 32, 11807-11826. [CrossRef]

41. Khademi, F.; Akbari, M.; Jamal, S.M.; Nikoo, M. Multiple linear regression, artificial neural network, and fuzzy logic prediction of 28 days compressive strength of concrete. Front. Struct. Civ. 2017, 11, 90-99. [CrossRef]

42. Ramyar, K.; Kol, P. Destructive and non-destructive test methods for estimating the strength of concrete. Cem. Concr. World. 1996, 2, 46-54.

43. Erdal, M. Prediction of the Compressive Strength of Vacuum Processed Concretes Using Artificial Neural Network and Regression Techniques. Sci. Res. Essays. 2009, 4, 1057-1065.

44. Cristofaro, M.T.; Viti, S.; Tanganelli, M. New predictive models to evaluate concrete compressive strength using the SonReb method. J. Build. Eng. 2020, 27, 100962. [CrossRef]

45. Samarin, A.; Dhir, R. Determination of In Situ Concrete Strength Rapidly and Confidently by Nondestructive Testing; ACI Symposium Publication: Detroit, MI, USA, 1987; Volume 82, pp. 77-94.

46. Faella, G.; Guadagnuolo, M.; Donadio, A.; Ferri, L. Calibrazione sperimentale del metodo SonReb per costruzioni della Provincia di Caserta degli anni '60 '80. In Proceedings of the 14th Anidis Conference, Bari, Italia, 18-22 September 2011.

47. Cristofaro, M.T.; D'Ambrisi, A.; De Stefano, M. Nuovi modelli previsionali per la stima della resistenza a compressione del calcestruzzo con il metodo Sonreb. In Proceedings of the Atti del XIII Convegno Nazionale L'Ingegneria Sismica, Bologna, Italia, 28 June-2 July 2009.

48. Hobbs, B.; Tchoketch, K.M. Non-destructive testing techniques for the forensic engineering investigation of reinforced concrete buildings. Forensic Sci. Int. 2007, 167, 167-172. [CrossRef]

49. Popovics, S.; Popovics, J. A critique of the ultrasonic pulse velocity method for testing concrete. NDT E Int. 1997, 30, 260.

50. Naik, T.R.; Malhotra, V.M.; Popovics, J.S. The ultrasonic pulse velocity Method. In Handbook on Nondestructive Testing of Concrete, 2nd ed.; CRC Press: Boca Raton, FL, USA, 2004.

51. Noguchi, T.; Nemati, K.M. Relationship between compressive strength and modulus of elasticity of High-Strength Concrete. J. Struct. Constr. Eng. 1995, 60, 1-10.

52. Lu, X.; Sun, Q.; Feng, W.; Tian, J. Evaluation of dynamic modulus of elasticity of concrete using impact-echo method. Constr. Build. Mater. 2013, 47, 231-239. [CrossRef]

53. Gutierres, P.A.; Canovas, M.F. The modulus of elasticity of high-performance concrete. Mater. Struct. 1995, 28, 559-568. [CrossRef]

54. Luo, Q.; Bungey, J. Using compression wave ultrasonic transducers to measure the velocity of surface waves and hence determine dynamic modulus of elasticity for concrete. Constr. Build. Mater. 1996, 4, 237-242.

55. GE 039. Guide to the In-Site and Laboratory Determination of the Static and Dynamic Moduli of Elasticity of Concrete; O.M.L.P.T.L. no. 1224/06.09.2001; Monitorul Oficial: Romania, 2001. Available online: https://www.monitoruloficial.ro/article--Publishing_ House--55.html (accessed on 3 November 2021). 
56. Salman, G.A. Density and Ultrasonic Pulse Velocity Investigation of Self-Compacting Carbon Fiber-Reinforced Concrete. J. Eng. Technol. 2018, 36, 88-99.

57. Panzera, T.H.; Rubio, J.C.; Bowen, C.R.; Vasconcelos, W.L.; Strecker, K. Correlation between Structure and Pulse Velocity of Cementations Composites. Adv. Cem. Res. 2009, 20, 101-108. [CrossRef]

58. ASRO. SR EN 12390-7. In Testing Hardened Concrete—Part 7: Density of Hardened Concrete; ASRO: Bucharest, Romania, 2019.

59. ASRO. SR EN 12390-3. In Testing Hardened Concrete-Part 3: Compressive Strength of Test Specimens; ASRO: Bucharest, Romania, 2019.

60. Everitt, B. The Cambridge Dictionary of Statistics; Cambridge University Press: Cambridge, UK; New York, NY, USA, 1998.

61. International Organization for Standardization. ISO 5725-1. In Accuracy (Trueness and Precision) of Measurement Methods and Results_Part 1: General Principles and Definitions; International Organization for Standardization: Geneva, Switzerland, 1994

62. Breysse, D.; Balayssac, J.-P.; Biondi, S.; Corbett, D.; Goncalves, A.; Grantham, M.; Luprano, V.A.M.; Masi, A.; Monteiro, A.V.; Sbartai, Z.M. Recommendation of RILEM TC249-ISC on non destructive in situ strength assessment of concrete. Mater. Struct. 2019, 52, 71. [CrossRef] 